\title{
The Effects of Reduction Mammaplasty on Serum Leptin Levels and Insulin Resistance
}

\author{
Hakan Uzun, ${ }^{1}$ Ozan Bitik, ${ }^{1}$ Yahya Baltu, ${ }^{2}$ Çiğdem Sönmez, ${ }^{3}$ and Ayşegül Öztürk Kaymak ${ }^{4}$ \\ ${ }^{1}$ Department of Plastic Reconstructive and Aesthetic Surgery, Hacettepe University Faculty of Medicine, Sihhiye, 06100 Ankara, Turkey \\ ${ }^{2}$ Department of Plastic Reconstructive and Aesthetic Surgery, Ankara Oncology Research and Training Hospital, \\ Yenimahalle, 06200 Ankara, Turkey \\ ${ }^{3}$ Department of Biochemistry, Ankara Oncology Research and Training Hospital, Yenimahalle, 06200 Ankara, Turkey \\ ${ }^{4}$ Department of Genetics, Ankara Oncology Research and Training Hospital, Yenimahalle, 06200 Ankara, Turkey
}

Correspondence should be addressed to Hakan Uzun; shakanuzuns@gmail.com

Received 20 June 2015; Accepted 4 October 2015

Academic Editor: Emanuel Christ

Copyright (C) 2015 Hakan Uzun et al. This is an open access article distributed under the Creative Commons Attribution License, which permits unrestricted use, distribution, and reproduction in any medium, provided the original work is properly cited.

Background. The reduction mammaplasty has been a well-executed and known procedure in which considerable amount of fatty tissue is removed from the body. The authors aimed to show the effects of the reduction mammaplasty on serum leptin levels and insulin resistance. Methods. 42 obese female patients who had gigantomastia were operated on. We recorded patients' demographic and preoperative data, including age, weight, height, and body mass index. Fasting serum leptin, glucose, and insulin levels were noted. Homeostasis model assessment scores were calculated. At the postoperative 8th week, patients were reevaluated in terms of above parameters assessing the presence of any difference. Results. Serum leptin levels were decreased postoperatively and the decrease was statistically significant. We were able to show a decrease in homeostasis model assessment score, which indicated an increase in insulin sensitivity, and this change was statistically significant. A significant correlation between body mass index and leptin change was found postoperatively. Conclusion. Reduction mammaplasty is not solely an aesthetic procedure but it decreases serum leptin levels and increases insulin sensitivity, which may help obese women to reduce their cardiovascular risk.

\section{Background}

The accumulation of excess fat is associated with an increased risk for diseases, such as type 2 diabetes mellitus, hypertension, hyperlipidemias, and cardiovascular disease [1]. Normal body weight is regulated by the presence of leptin, an adipocyte derived hormone that acts on the brain to regulate food intake. It is secreted from adipocytes, mammary glands, placenta, stomach, and skeletal muscle. Leptin, a product of the obese (ob) gene, signals the hypothalamus to reduce appetite and increase energy expenditure [2]. It is a neuroendocrine protein with biological activities such as appetite regulation, energy homeostasis, bone formation, reproductive function, and angiogenesis.

Leptin is correlated with weight; its levels increase in association with increasing weight and fat mass. In obese people, it is overexpressed as compared with nonobese patients. Recent studies have figured out that leptin may help regulate blood volume and blood pressure in healthy individuals. However, in resistant situations like obesity, elevated leptin levels may lead to hypertension, renal and cardiovascular damage [3].

Body contouring procedures, such as liposuction and abdominoplasty, have increased in demand lately due to their relative safety $[4,5]$. An association between peripheral fat removing by liposuction and decreasing of leptin levels already has been demonstrated [6]. Recently, abdominoplasty has been shown to decrease serum leptin concentrations as well [7].

Insulin is a critical factor for adipocyte metabolism. It has been known that insulin stimulates leptin synthesis and hyperinsulinemic conditions induce leptin resistance and hyperleptinemia $[8,9]$. It has been shown that liposuction ameliorates insulin resistance [9] but abdominoplasty has been failed to change insulin sensitivity [7].

Previous studies suggest that breast volume or more precisely breast adipose tissue is linked to visceral fat and may 
TABLE 1: The mean age of the patients and the mean amount of reduction according to type of reduction mammoplasty.

\begin{tabular}{lcrr}
\hline & \multicolumn{2}{c}{ Type of reduction mammaplasty } & Total $(n: 42)$ \\
& Superomedial pedicle & Inferior pedicle $(n=14)$ & $47,67 \pm 10,90$ \\
\hline Age & $44,79 \pm 10,83$ & $53,43 \pm 8,79$ & $1.954,43 \pm 505,81$ \\
Amount of reduction $(\mathrm{g})$ & $1.844,14 \pm 508,31$ & $2.175,00 \pm 437,80$ & \\
\hline
\end{tabular}

be an independent risk factor. The reduction mammaplasty has been a well-executed and known procedure in which considerable amount of fatty tissue is removed from the body. Its effects on serum leptin levels and insulin resistance have not been studied yet. In the present study, the authors aimed to show the effects of the reduction mammaplasty on serum leptin levels and insulin resistance.

\section{Methods}

The present study was conducted according to the Declaration of Helsinki. The study was approved by Institutional Review Board. Informed consent was obtained from each patient. We recorded patients' demographic and preoperative data, including age, weight, height, and body mass index (BMI). BMI was calculated as weight in kilograms divided by the square of height in meters. Fasting serum glucose and insulin levels were noted. Insulin sensitivity in the fasting state was assessed with homeostasis model assessment (HOMA) and calculated with the following formula: fasting plasma glucose $(\mathrm{mmol} / \mathrm{L}) \times$ fasting serum insulin $(\mathrm{mU} / \mathrm{mL})$ divided by 25 , as described by Matthews et al. [10]. High HOMA scores denote low insulin sensitivity.

In order to measure fasting leptin levels, blood samples were divided into two aliquots and immediately stored frozen at $-20^{\circ} \mathrm{C}$ until required for analysis. Serum leptin levels were determined by using commercially available LeptinEASIA (DIAsource ImmunoAssays S.A., Louvain-la-Neuve, Belgium) kit that was an Enzyme Amplified Sensitivity Immunoassay performed on microtiter plate. The assay was performed according to the manufacturer's protocol. The detection limit was $0.04 \mathrm{ng} / \mathrm{mL}$. The optical density values for the plate were determined within $30 \mathrm{~min}$, using a microplate reader ELX 800 (Bio-Tek Instruments, Inc., Vermont, USA).

In total, 42 obese female patients who had gigantomastia were operated on. Patient demographics and the type of reduction mammaplasty were given in tables. At the postoperative 8 th week, patients were reevaluated in terms of above parameters assessing the presence of any difference.

2.1. Statistical Analysis. Data were analyzed using SPSS version 22.0 (IBM statistics for Windows version 22, IBM Corporation, Armonk, New York, USA). The paired samples $t$-test was used to examine the change on the basis of repeated measurements of the dependent variables. The changes within subgroups (superomedial pedicle/inferior pedicle) were then compared with each other by the general linear model repeated ANOVA (Wilks' Lambda). Pearson's correlation test and Spearman's rho test were used to determine whether any correlation existed between variables. Quantitative variables were indicated as mean and standard deviation $( \pm)$. $p$ value of $<0.05$ reflected statistical significance.

\section{Results}

The mean age of the patients was $47,67 \pm 10,90.28$ patients underwent superomedial pedicle reduction mammaplasty and 14 patient underwent inferior pedicle reduction mammaplasty (Table 1 ). The amount of breast tissue removed was $1.954,43 \pm 505,81 \mathrm{~g}$ (range $870 \pm 3,790 \mathrm{~g}$ ). Preoperatively mean concentrations of serum glucose, insulin, and leptin were 5,91 $\pm 0,97 \mathrm{mmol} / \mathrm{L}, 13,8 \pm 11,26 \mathrm{mIU} / \mathrm{L}$, and 25,90 \pm $11,17 \mathrm{ng} / \mathrm{mL}$, respectively. Postoperatively mean concentrations of serum glucose, insulin, and leptin were 5,20 \pm $0,56 \mathrm{mmol} / \mathrm{L}, 11,5 \pm 9,30 \mathrm{mIU} / \mathrm{L}$, and $18,68 \pm 9,30 \mathrm{ng} / \mathrm{mL}$, respectively.

Serum leptin levels were decreased postoperatively and the decrease was statistically significant $(p<0.05)$. It means that the serum leptin levels decreased as the amount of breast reduction increased. We were able to show a decrease in HOMA score $(3,11 \pm 1,84$ preoperatively, $2,48 \pm 1,6$ postoperatively), which indicated an increase in insulin sensitivity, and this change was statistically significant $(p<0.05)$. A significant correlation between BMI and leptin change was found postoperatively (Pearson's correlation coefficient $r=$ 0.037, $p<0.05$ ).

The clinical characteristics and the metabolic profile before and after surgery are shown in Table 2, which shows how BMI, HOMA score, glucose, insulin, and leptin levels significantly decreased after the surgery.

\section{Discussion}

Obesity is related to many diseases: in particular excessive visceral fat is an important risk factor for the development of insulin resistance and atherosclerosis and, consequently, the establishment of conditions such as type 2 diabetes, cardiovascular disease, metabolic syndrome, and also some types of cancer $[11,12]$. Although the molecular mechanisms related to metabolic changes induced by excessive visceral fat have not yet been completely understood, the changes in adipokine production seem to play a crucial role in the metabolic alteration related to obesity [12].

An association between peripheral fat removing by abdominoplasty and decreasing of leptin levels already has been demonstrated [7]. Breast tissue consists of $60 \%$ adipose tissue [13] and is considered to belong to the truncal fat [14], which has been recently examined for its influence on cardiometabolic risk [15]. It has been shown that breast size 
TABLE 2: The clinical characteristics and the metabolic profile before and after surgery.

\begin{tabular}{lccccc}
\hline & BMI $\left(\mathrm{kg} / \mathrm{m}^{2}\right)$ & Leptin $(\mathrm{ng} / \mathrm{mL})$ & Glucose $(\mathrm{mmol} / \mathrm{L})$ & Insulin $(\mathrm{mIU} / \mathrm{L})$ & HOMA score \\
\hline Preoperative & $33,94 \pm 2,39$ & $25,90 \pm 11,17$ & $5,76 \pm 0,94$ & $13,8 \pm 11,26$ & $3,11 \pm 1,84$ \\
Postoperative & $32,12 \pm 2,08$ & $18,68 \pm 9,30$ & $5,20 \pm 0,56$ & $11,5 \pm 9,30$ & $2,48 \pm 1,6$ \\
Change (before-after) & $1,82 \pm 0,98$ & $7,21 \pm 4,91$ & $0,57 \pm 0,60$ & $2,30 \pm 1,23$ & $0,63 \pm 0,52$ \\
$p$ & 0.001 & 0.001 & 0.001 & $<0.001$ & $<0.001$ \\
\hline
\end{tabular}

in late adolescence may predict the risk of developing type 2 diabetes in middle age independent of BMI and waist circumference [16].

We hypothetically expected to show a significant relationship between amount of reduction in breasts and serum leptin levels, and we were able to show significant correlation probably because adipose tissue is the main source of leptin. Breast size has been known as an indicator of the visceral fat. It has been shown that women with greater breast size for a given BMI and waist circumference had more visceral adipose tissue than women with smaller breast volume [17]. However Schautz et al. have reported that breast adipose tissue was not associated with the proportion of visceral fat [15]. They have shown that there was also no independent association between breast adipose tissue and cardiometabolic risk factors or plasma levels of adipokines. In contrast to this study, Vinci et al. have demonstrated that reduction mammaplasty is a surgical procedure associated with a significant improvement in adiponectin level [12].

Insulin is an important mediator for adipocyte metabolism. Many studies have indicated the association between insulin resistance and serum leptin levels. These findings suggest that hyperinsulinemia induces leptin resistance and hyperleptinemia $[18,19]$. In the present study, reduction mammaplasty did have a significant effect on insulin sensitivity. Our results were similar to the results of the study done by González-Ortiz et al. [20] in which they did show an improvement in insulin sensitivity after large volume liposuction in obese women although the same group had later demonstrated that there was no correlation between abdominoplasty and insulin sensitivity [7]. They concluded that insulin sensitivity is associated with visceral fat but not with subcutaneous fat. However the lifestyle change occurred after reduction mammaplasty and decrease in BMI may contribute to the increase in insulin sensitivity.

Circulating leptin levels are influenced by a variety of metabolic active factors, the most prominent of which is insulin [21]. Insulin stimulates both leptin secretion and leptin mRNA levels [22]. Therefore an increase in insulin sensitivity is expected to decrease the serum leptin levels. We think that the decrease in serum leptin levels may be related to the breast fat and the breast parenchyma removal not solely because of increase in insulin sensitivity.

We were also able to demonstrate a positive correlation between BMI and serum leptin levels as already shown by various studies. The leptin production rate in adipose tissue is directly proportional to the degree of adiposity [23]. The serum leptin concentrations in healthy men and women are positively correlated with both BMI and total body fat [24]. Although the decrease in BMI was not associated with
TABLE 3: Comparison of the serum leptin levels according to the type of reduction mammoplasty.

\begin{tabular}{lcc}
\hline $\begin{array}{l}\text { Serum leptin levels } \\
(\mathrm{ng} / \mathrm{mL})\end{array}$ & \multicolumn{2}{c}{ Type of reduction mammaplasty } \\
Superomedial pedicle & Inferior pedicle \\
\hline Before & $26,98 \pm 12,27$ & $23,74 \pm 8,54$ \\
After & $18,13 \pm 10,22$ & $19,79 \pm 7,32$ \\
Change & $8,85 \pm 4,81$ & $3,95 \pm 3,28$ \\
$p$ & 0.001 & 0.011 \\
$p^{1}$ & & 0.001 \\
\hline
\end{tabular}

$p$ indicates the difference within each group.

$p^{1}$ indicates the difference between two groups.

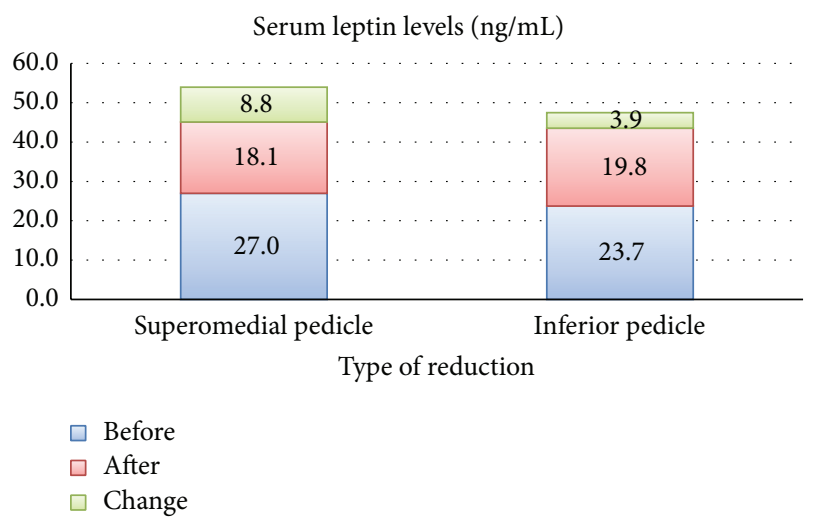

Figure 1: Association between serum leptin levels and type of reduction mammaplasty.

the amount of reduction made (Pearson's correlation coefficient $r=0.128, p=0.420$ ), we may speculate that the lifestyle changes, which comprised an increase in exercise and a decrease in dietary intake of food, significantly contributed to the decrease in BMI.

In our study, we interestingly found that the type of the pedicle chosen for the reduction mammaplasty had some relation with the serum leptin levels (Table 3 ). The patients for whom the superomedial pedicle was used to transport the nipple areola complex had higher decrease in serum leptin levels than the patients for whom the inferior pedicle was used (Figure 1) although the mean amount of reduction in inferior pedicle technique was higher than that of superomedial technique. The mean age of patients with superomedial technique being used was lower than that of the patients with inferior technique. Age related changes in serum leptin levels are still controversial. Isidori et al. have shown that in adult humans of different body weight serum leptin gradually 
declines during aging; leptin reduction is higher in women than in men, but it is independent of BMI and other age related endocrine changes [25]. However Baranowska et al. have confirmed that in elderly humans of normal body weight the plasma leptin levels were lower than in middle-aged obese persons [26]. We could not find out any study that investigates which part of the breast has more capacity to express leptin. According to the results we obtained we can speculate that inferior part of the breast has more leptin expression than the superior part. However, this finding, which may also be important for breast cancer research, should be investigated and clarified by further studies.

There were limitations that should be considered when interpreting our results. The morbid obese patients which were absent in the present study can be included in another study design. We are also aware that our small sample size could have limited our power to detect meaningful associations; however, the preliminary findings reported herein are useful for generating new hypotheses that can be investigated in larger studies.

\section{Conclusion}

Reduction mammaplasty is not solely an aesthetic procedure but it decreases serum leptin levels and increases insulin sensitivity, which may help obese women to reduce their cardiovascular risk.

\section{Conflict of Interests}

The authors declare that there is no conflict of interests regarding the publication of this paper.

\section{Acknowledgments}

The authors would like to thank Elif Akdemir for her enormous support in sample analysis and Hüseyin Candan for his great work in statistical analysis.

\section{References}

[1] K. E. Kip, O. C. Marroquin, D. E. Kelley et al., "Clinical importance of obesity versus the metabolic syndrome in cardiovascular risk in women: a report from the Women's Ischemia Syndrome Evaluation (WISE) study," Circulation, vol. 109, no. 6, pp. 706-713, 2004.

[2] K. Michalakis and C. le Roux, "Gut hormones and leptin: impact on energy control and changes after bariatric surgery-what the future holds," Obesity Surgery, vol. 22, no. 10, pp. 1648-1657, 2012.

[3] S. Appachi and S. R. Kashyap, "Adiposopathy and cardiovascular disease: the benefits of bariatric surgery," Current Opinion in Cardiology, vol. 28, no. 5, pp. 540-546, 2013.

[4] A. Matarasso, R. W. Kim, and J. G. Kral, "The impact of liposuction on body fat," Plastic and Reconstructive Surgery, vol. 102, no. 5, pp. 1686-1689, 1998.

[5] M. Chaouat, P. Levan, B. Lalanne, T. Buisson, P. Nicolau, and M. Mimoun, "Abdominal dermolipectomies: early postoperative complications and long-term unfavorable results," Plastic and Reconstructive Surgery, vol. 106, no. 7, pp. 1614-1618, 2000.

[6] R. Talisman, N. Belinson, D. Modan-Moses et al., "The effect of reduction of the peripheral fat content by liposuction-assisted lipectomy (SAL) on serum leptin levels in the postoperative period: a prospective study," Aesthetic Plastic Surgery, vol. 25, no. 4, pp. 262-265, 2001.

[7] E. Martínez-Abundis, C. A. Molina-Villa, M. González-Ortiz, J. A. Robles-Cervantes, and J. A. Saucedo-Ortiz, "Effect of surgically removing subcutaneous fat by abdominoplasty on leptin concentrations and insulin sensitivity," Annals of Plastic Surgery, vol. 58, no. 4, pp. 416-419, 2007.

[8] R. S. Surwit, A. E. Petro, P. Parekh, and S. Collins, "Low plasma leptin in response to dietary fat in diabetes- and obesity-prone mice," Diabetes, vol. 46, no. 9, pp. 1516-1520, 1997.

[9] G. Giugliano, G. Nicoletti, E. Grella et al., "Effect of liposuction on insulin resistance and vascular inflammatory markers in obese women," British Journal of Plastic Surgery, vol. 57, no. 3, pp. 190-194, 2004.

[10] D. R. Matthews, J. P. Hosker, A. S. Rudenski, B. A. Naylor, D. F. Treacher, and R. C. Turner, "Homeostasis model assessment: insulin resistance and $\beta$-cell function from fasting plasma glucose and insulin concentrations in man," Diabetologia, vol. 28, no. 7, pp. 412-419, 1985.

[11] C. Gasteyger and A. Tremblay, "Metabolic impact of body fat distribution," Journal of Endocrinological Investigation, vol. 25, no. 10, pp. 876-883, 2002.

[12] V. Vinci, S. Valaperta, M. Klinger et al., "Metabolic implications of surgical fat removal: increase of adiponectin plasma levels after reduction mammaplasty and abdominoplasty," Annals of Plastic Surgery, 2014.

[13] N. Cruz-Korchin, L. Korchin, C. González-Keelan, C. Climent, and I. Morales, "Macromastia: how much of it is fat?" Plastic and Reconstructive Surgery, vol. 109, no. 1, pp. 64-68, 2002.

[14] T. J. Saunders, L. E. Davidson, P. M. Janiszewski, J.-P. Després, R. Hudson, and R. Ross, "Associations of the limb fat to trunk fat ratio with markers of cardiometabolic risk in elderly men and women," Journals of Gerontology-Series A Biological Sciences and Medical Sciences, vol. 64, no. 10, pp. 1066-1070, 2009.

[15] B. Schautz, W. Later, M. Heller, M. J. Müller, and A. BosyWestphal, "Associations between breast adipose tissue, body fat distribution and cardiometabolic risk in women: crosssectional data and weight-loss intervention," European Journal of Clinical Nutrition, vol. 65, no. 7, pp. 784-790, 2011.

[16] J. G. Ray, A. P. Mohllajee, R. M. van Dam, and K. B. Michels, "Breast size and risk of type 2 diabetes mellitus," CMAJ, vol. 178, no. 3, pp. 289-295, 2008.

[17] P. M. Janiszewski, T. J. Saunders, and R. Ross, "Breast volume is an independent predictor of visceral and ectopic fat in premenopausal women," Obesity, vol. 18, no. 6, pp. 1183-1187, 2010.

[18] M. González-Ortiz, E. Martínez-Abundis, and J. M. MoraMartínez, "Acute effect of physiologic hyperinsulinaemia on serum leptin concentration in healthy young people," Acta Diabetologica, vol. 37, no. 2, pp. 83-86, 2000.

[19] A. G. Hoppin and L. M. Kaplan, “The leptin era: new insight into the mechanisms of body weight homeostasis," Journal of Pediatric Gastroenterology and Nutrition, vol. 29, no. 3, pp. 250264, 1999.

[20] M. González-Ortiz, J. A. Robles-Cervantes, L. CárdenasCamarena, R. Bustos-Saldaña, and E. Martínez-Abundis, 
"The effects of surgically removing subcutaneous fat on the metabolic profile and insulin sensitivity in obese women after large-volume liposuction treatment," Hormone and Metabolic Research, vol. 34, no. 8, pp. 446-449, 2002.

[21] T. Kaur and Z.-F. Zhang, "Obesity, breast cancer and the role of adipocytokines," Asian Pacific Journal of Cancer Prevention, vol. 6, no. 4, pp. 547-552, 2005.

[22] P. Leroy, S. Dessolin, P. Villageois et al., "Expression of ob gene in adipose cells. Regulation by insulin," The Journal of Biological Chemistry, vol. 271, no. 5, pp. 2365-2368, 1996.

[23] S. Klein, S. W. Coppack, V. Mohamed-Ali, and M. Landt, "Adipose tissue leptin production and plasma leptin kinetics in humans," Diabetes, vol. 45, no. 3, pp. 984-987, 1996.

[24] T. Thomas, B. Burguera, L. J. Melton III et al., "Relationship of serum leptin levels with body composition and sex steroid and insulin levels in men and women," Metabolism: Clinical and Experimental, vol. 49, no. 10, pp. 1278-1284, 2000.

[25] A. M. Isidori, F. Strollo, M. Moré et al., "Leptin and aging: correlation with endocrine changes in male and female healthy adult populations of different body weights," Journal of Clinical Endocrinology and Metabolism, vol. 85, no. 5, pp. 1954-1962, 2000.

[26] B. Baranowska, W. Bik, A. Baranowska-Bik et al., "Neuroendocrine control of metabolic homeostasis in Polish centenarians," Journal of Physiology and Pharmacology, vol. 57, supplement 6, pp. 55-61, 2006. 


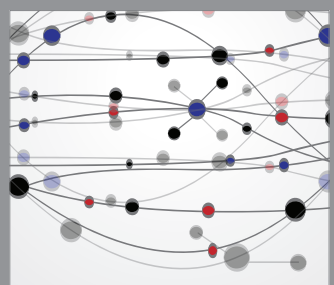

The Scientific World Journal
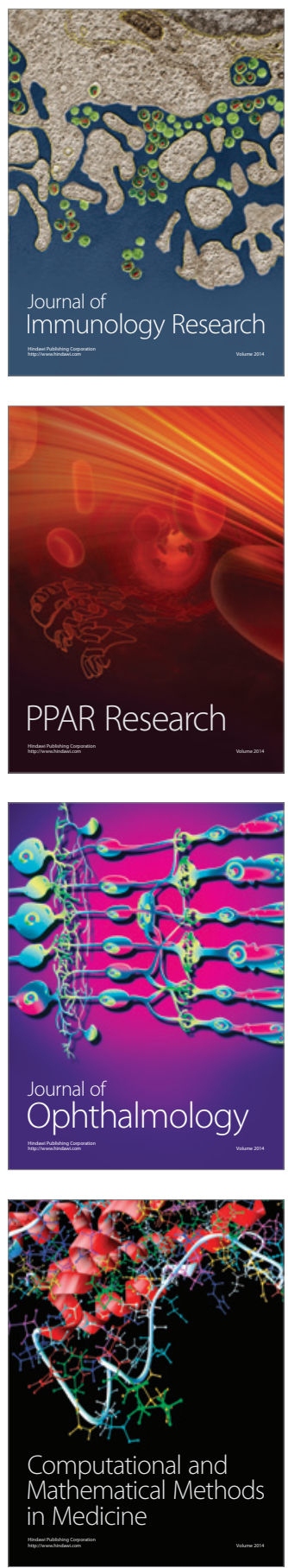

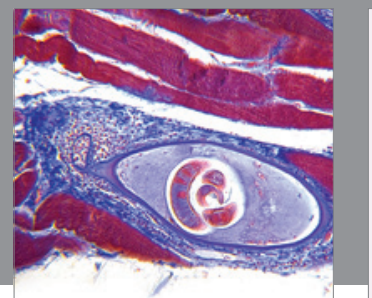

Gastroenterology

Research and Practice
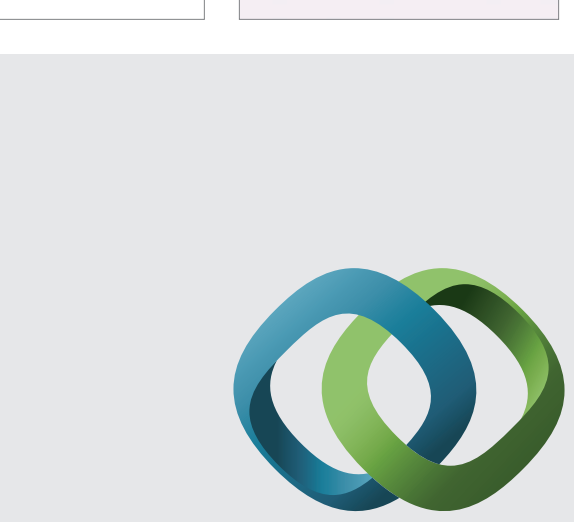

\section{Hindawi}

Submit your manuscripts at

http://www.hindawi.com
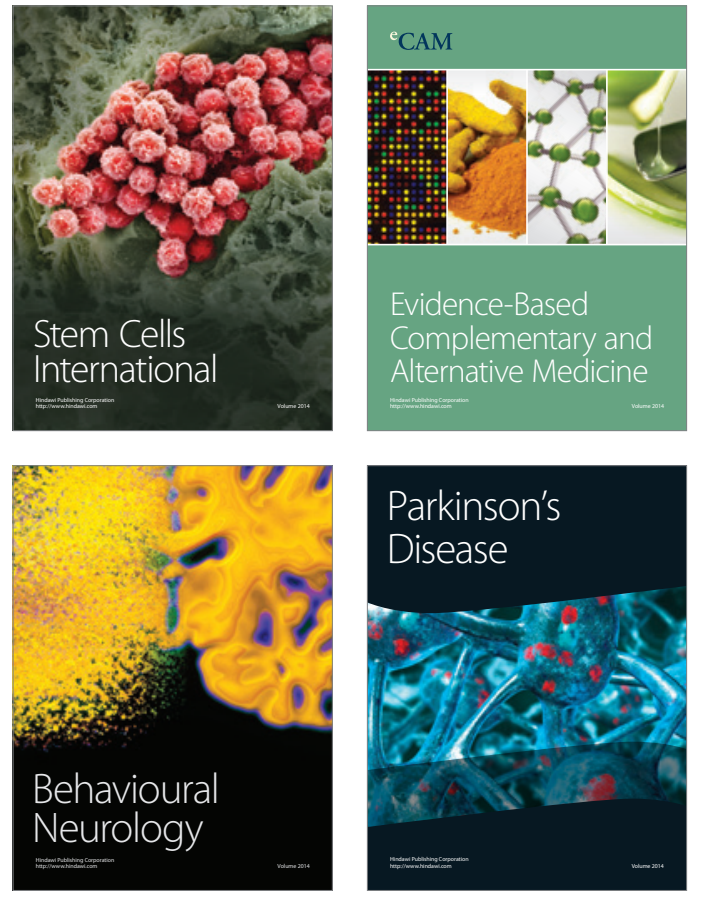
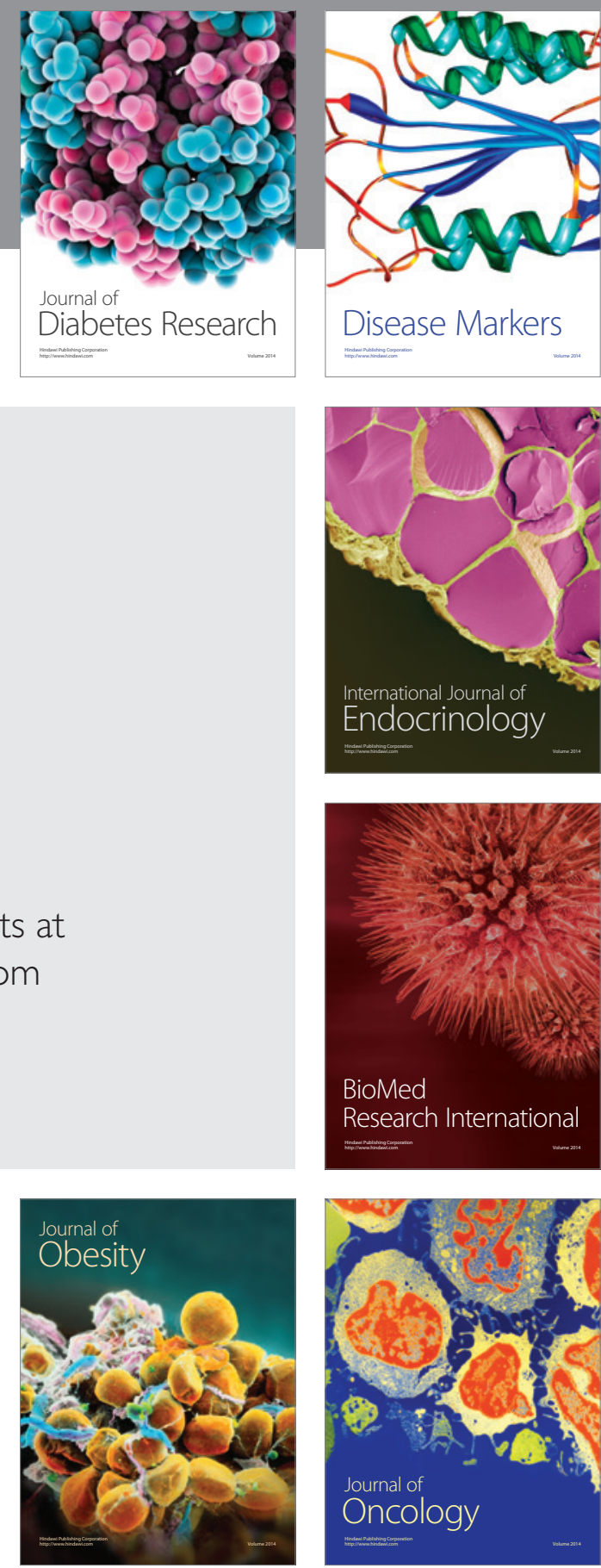

Disease Markers
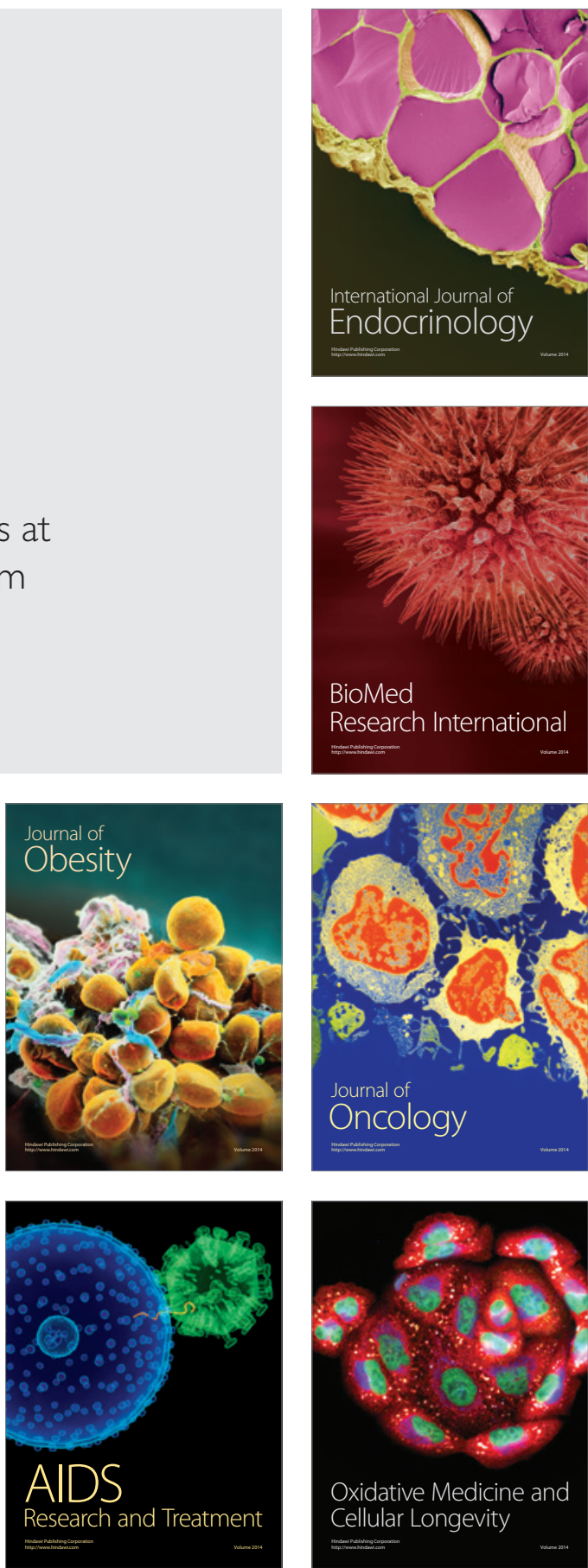